\title{
A Study on the 'Flexibility' of Information Systems (Part 1): Why Do They Need to Be Flexible?
}

\author{
Masaru Furukawa ${ }^{1} \&$ Akira Minami $^{2}$ \\ ${ }^{1}$ Faculty of Economics, University of Toyama, Japan \\ ${ }^{2}$ Toyama Prefectural University, Japan \\ Correspondence: Masaru Furukawa, University of Toyama, 3190, Gofuku, Toyama-city, Toyama, 930-8555, \\ Japan. Tel: 81-76-445-6477. E-mail: frukawa@eco.u-toyama.ac.jp
}

Received: June 24, 2013

doi:10.5539/ijbm.v8n20p48
Accepted: July 31, 2013

Online Published: September 22, 2013

URL: http://dx.doi.org/10.5539/ijbm.v8n20p48

\begin{abstract}
Despite the great strides that MIS have made in their coverage, their development and technological renovation have often failed to be in satisfactory sync with the ever-changing business needs. Our view is that this failure is attributable to the fact that these computer-based systems have not equipped themselves with the adequate flexibility needed to respond promptly to business environmental changes.

This study proposes a methodology for planning the implementation of flexible information system (IS) aimed at helping business organizations respond quickly to the environmental changes. First, we consider the meanings of business agility. Next, we elucidate the nature of the difficulties afflicting IS management through an analysis of the technology-organization relationship. We then define IS flexibility and its enhancement approach as a solution, and propose our concept of 'penalty of change,' which should be practical for defining and evaluating IS flexibility in terms of cost and time.
\end{abstract}

Keywords: business agility, inter-corporate competition, IS value, IS reward, IS flexibility, POC (penalty of change)

\section{Introduction}

Information systems (IS) for management launched in the '70s were first used to automate individual business processes in an enterprise and later to build an integrated system covering the entire enterprise. Subsequently, systems integration was extended beyond the boundaries of individual enterprises, primarily for the systematization of supply chain management. However, their development and technological renovation have often failed to be in satisfactory sync with the ever-changing strategic needs of the enterprises concerned. Previous Studies suggest that such dissatisfaction arose from both behavioral/organizational and technological issues. Our view is that this dissatisfaction is attributable to the fact that these computer-based systems have not equipped themselves with the adequate structural flexibility needed for prompt response to changes in the business environment, and that technological flexibility will propose the solution to behavioral or organizational issues.

This perception motivated us to propose a methodology for planning the implementation of structurally flexible information systems aimed at helping business organizations respond quickly and easily to changes in their business environment. This paper, Part 1 of our study, addresses the question of "why information systems need to be flexible." Part 2 is devoted to the discussion of "how we can make them flexible."

In the first part of this paper, we define the role that an IS division should play in assisting its organization's "business agility" and intercorporate competitiveness. We then define our concepts of IS reward, IS value, and IS flexibility, and propose the idea of penalty of change (POC), which we deem usable to quantitatively define and evaluate IS flexibility in terms of cost and time. Next, we elucidate the root of the difficulties afflicting IS management through an analysis of the technology-organization relationship and a historical review of technological innovation. In the last part, we discuss the need for IS flexibility enhancement as a solutional approach.

\section{Previous Studies and Research Question}

Information Economics (Parker \& Benson, 1988) identified sixtypes of IS value: investment, management 
information, competition, strategy support, competitive edge, and information technology infrastructure (ITI). It defined the value of ITI that supports the generation of other values. Duncan (1995) discussed the concepts of IT resource management, including technological architecture, planning alignment, and human resource skills, all of which are linked to definitions of ITI, and introduced the concept that flexibility is either developed or thwarted in deferent circumstances. Byrd and Turner (2000) explored the predictive validity of the instruments with possible antecedent and consequent variables. The scheme to evaluate flexibility as a degree of freedom in the assumed operation methods seems analogous to the evaluation of freedom in tool exchanges or mechanical operations as flexibility in flexible manufacturing systems (FMSs).

Insufficient flexibility can limit the success of an IS by preventing its use in certain circumstances and necessitating exception handling. Also, insufficient flexibility can reduce the overall lifetime of a system. However, excessive flexibility can limit IS success by limiting usability (Silver, 1991) and increasing complexity (Economist, 2004), thus requiring larger investments, longer implementation time, and higher subsequent operating and maintenance costs (Soh, et al., 2003).

Today, IS managers face various choices regarding IS flexibility, ranging from turnkey systems with little room for subsequent changes to IS architectures with numerous options for future change (Rumbaugh et al., 1991). Currently, various IT innovations are available that appear effective, yet require significant upfront investments.

The introduction to Gebauer\&Schober (2006) indicated "that practical evidence as reported to the authors by a number of IS managers and consultants in Europe and in the United States suggests that in lieu of clear guidelines regarding the economic management of MIS flexibility, MIS investment decisions may be based on factors such as short-term political considerations, risk aversion, tight budgets, and 'me-too' desires at the expense of MIS flexibility that may only pay out in the longer term".

IS research has addressed IS effects on organizational flexibility and competitive advantage (Palanisamy \& Sushil, 2003) and the typically contradictory IS effects on organizational flexibility and efficiency (Allen \& Boynton, 1991; Robey \& Boudreau, 1999). However, thus far, the economics of IS flexibility has received comparatively little attention. Nevertheless, research in system requirement engineering, which refers to the process of formulating, documenting, and maintaining software requirements, has long highlighted that nonsystematic and unstructured analyses of IS requirements can lead to suboptimal results (Robinson \& Pawlowski, 1999).

On the basis of this awareness, Gebauer and Schober (2006) defined IS flexibility as efficiency in the use and provision (or change) of the system function for supporting operativity not as a tool but as a business process, and proposed a scheme for evaluating a given business process in terms of cost efficiency.

In a study connecting corporate management and ITI, Fink and Neumann (2009) used a resource-based view of the firm and a dynamic capabilities perspective to account for the competitive effects of flexibility. They also reported that the range of managerial ITI capabilities, which were positively affected by all areas of IT personnel knowledge and skills, was responsible for the competitive effects of ITI-enabled flexibility.

Furukawa (2000) expanded "the probabilistic approach based on prediction proposed as a flexibility evaluation method of FMS" (Chryssolouris \& Lee, 1992) and applied it to ITI evaluation as a method of analyzing ITI value in Information Economics. The proposal on IS flexibility evaluation is based on the concept that the demand for change in a business process needs provision or change in IS function, which requires cost and time as $P O C$. Moreover, this research proposed a plan to prepare ITI equipped with sufficient flexibility to absorb future changes in demands, thus acquiring intercorporate competitive advantages. That is, this research 1) is premised on the importance of ITI in intercorporate competition (Fink \& Neumann, 2009); 2) sets up cost efficiency to support business processes as a problem in the provision (or change) of an IS function (Gebauer \& Schober, 2006); and 3) is challenging with respect to developing ITI as a tool equipped with necessary the flexibility (Byrd \& Turner, 2000).

On the basis of their research findings, Furukawa (2000) proposed a practical method for IS managers to prepare necessary and sufficient $I S$ flexibility at a time when they face a variety of choices regarding this flexibility (i.e., various option selections with respect to IS flexibility). In addition to proposing the theory of IS flexibility, a more general goal is to establish the relevance of IS value evaluation for successful IS management and to link business value with IS value through IS flexibility. Therefore, we inherit the objective of Furukawa (2000) and clarify the countermeasures of the problem that an IS manager faces, and we set up our research question in this paper as, "why do information systems need to be flexible?"

To begin with our discussion, we survey a typical IS manager's daily state of affairs in a firm. 


\section{IS Manager's Problems}

The mission of IS divisions is to offer IS functions to end-user organizations, i.e., an indispensable support for the pursuit of their business strategies. However, an IS is primarily technology-based and grows in scale and complexity. Therefore, despite the importance of the participation of end-users, an organization planning to implement computer-based systems has no choice but to allow its engineers to take the lead in development, unfamiliar as they may be with business matters. This fact has frequently resulted in unavoidable communication gaps between the engineers and end-users of the system and in the consequent predicament of the manager of the IS division caught between them. Moreover, from the early stages of the introduction of IS to the present day, no substantial changes have occurred in the situations where the manager of a corporate IS division (hereafter IS manager) finds himself.

Table 1. IS manager's problems

\begin{tabular}{cl}
\hline End-user & - We can hardly believe that implementing a new application system will take as long as two years. We cannot wait for \\
& such a long time. \\
& - We cannot see why such a small modification will take one month. \\
& - This system does not meet our needs. \\
& - We wish we had a computer of our own in our division. \\
\hline Executive & - Personnel expenses are increasing too much. \\
director & - It is taking too much time. \\
& - Why can't we do it ourselves when our competitor is already doing it? \\
\hline Engineer & - Are you telling us to work still harder to develop new systems? \\
& - We already have our hands full with maintenance work. \\
& - Add five more workers, please. \\
& - It takes us at least one year to train a new recruit to become a full-fledged worker. \\
& - Our end-users should just be more cooperative with us. \\
\hline Note: IBM Japan handout meant for user corporations in the middle of the 1980s. Source: Furukawa (1989).
\end{tabular}

Table 1 is an excerpt from an IBM Japan handout meant for user corporations (the illustration of an IS manager racking his brains over some of the problems that he faces is impressive). Table 1 enumerates the complaints that the people concerned make to the IS division.

End-users voice dissatisfaction with the service provided, referring to the division's inability to promptly deliver required application functions and to the failure of these functions to meet their practical needs. Moreover, end-users seem to attribute these issues to the suspected inadequacy of both development capabilities and hands-on experience of the division because they go so far as to express their doubt about the raison d'être of an organization-wide IS.

Corporate executives complain about the cost of IS management, especially with respect to increasing personnel expenses. They can hardly tolerate the situation, given the perceived inferiority of their IS division relative to those of other companies with respect to the ability to promptly deliver on urgent needs.

The engineers, busy with system development, system maintenance, and training of new recruits, demand correction of their chronic work overload.

In short, Table 1 clearly shows that the IS division has secured the satisfaction of neither the customers nor the staff. The IS manager is literally hemmed in on all sides.

\section{Role of IS in Intercorporate Competition}

\subsection{Business Environment Around the IS Division}

\subsubsection{Today's Corporate Management}

We consider the IS manager's predicament in the broader context of today's corporate management environment. In a business organization, the company's end-users and executives are the customers of the IS division. These IS customers work in a rapidly changing business environment in which an intricate intertwinement exists between "external pressure," in the form of market change factors such as international politics and energy problems, and "internal pressure," in the form of cost-increasing factors such as technological renovation, shorter product lifecycles, and workforce shrinkage attributable to a declining birthrate and an aging society. These customers are continuously challenged to respond on an ad hoc basis to such dizzying changes. 
We consider this situation in concrete terms, taking the competitive development of industrial products amid a growing trend toward shorter lifecycles as an example. Even a highly efficient and functionally superior product developed by a company is apt to see its market price and profitability decline almost immediately after it is put on the market. This phenomenon occurs because the value of the product in question declines in relative terms as it is compelled to compete with other brands that are of equivalent or superior quality. Therefore, to continue securing profits, the company has to develop and market one new product after another in rapid succession before the decline in its value is apparent. That is, a delay in the development of new products is a recipe for the defeat and mortal wounding of the company engaged in intercorporate competition. Goldratt (1997) paid attention to the importance of this problem and proposed a solution by elucidating the causes for overdue project development.

\subsubsection{Business Agility for Intercorporate Competition}

Regarding competitive product development, Hammer and Champy (1993) referred to the development of the disposable camera by the Eastman Kodak Company as a case in point of concurrent engineering. Kodak decided to use this engineering method to develop its new model with a view to pre-empting Fuji Photo Film Co. Ltd., which had marketed the disposable camera ahead of other companies in its attempt to corner the market. Kodak adopted this parallel type of development approach and managed to develop its new model in no more than 38 weeks. Kodak would have required no less than 70 weeks had it adopted a conventional sequential or serial type approach, such as the Waterfall Model. This reduction in lead time, as well as the additional benefit of a $25 \%$ cost saving, enabled Kodak to prevent its rival from monopolizing the market.

Of no less importance for the survival of companies exposed to fierce competition is speed of their IS development. In this area, attempts are also being made to reduce development lead time by reorienting from the Waterfall type approach and its inadequacies in favor of a new model, referred to as "agile management" (Anderson, 2004).

Although these methods are now the focus of increasing research efforts, most studies are still based on XP (extreme programming), Scrum (Takeuchi \&Nonaka, 1986; Hulet, 2004), and other industry-driven foundations, with little or no conceptual studies on IS development's existing agility. As a result, this study proposes that agile methods and the associated literature in its current state have several significant conceptual shortcomings, including lack of clarity or theoretical glue, parsimony, limited applicability, and naivety regarding the evolution of the concept of agility in fields outside systems development. Furthermore, these shortcomings have significant implications for practitioners, rendering agile method comparison and many other activities very difficult, especially in instances such as distributed development and large teams that are not conducive to many of the commercial agile methods (Conboy, 2009).

Mathiassen \& Pries-Heje (2006) referred to business agility as a relatively new paradigm painted as a solution for maintaining competitive advantage during times of uncertainty and turbulence in the business environment (Sharifi \& Zhang, 2001). Merriam-Webster Online defines an agile mind as having a quick, resourceful, and adaptable character. Therefore, agile organizations respond quickly, are resourceful, and are able to adapt to their environment. Quickness is about the speed with which an organization can respond to customer requests, market dynamics, and emerging technology options, including the time to sense relevant events, the time to interpret what is happening and assess the consequences for the organization, the time to explore options and decide which actions to take, and the time to implement appropriate responses (Haeckel, 1999). Resources are about the organization's available capabilities including people, technology, processes, and knowledge. They can be tangible as well as intangible, and provide the basis for conducting business and instantiating change (Haeckel, 1999). Adaptability is about how well the organization responds to changing demands, threats, or opportunities, which requires the ability to learn as well as have flexible processes and products that can be reconfigured without extensive additional costs (Haeckel, 1999; Dove, 2001). Agility is concerned with economies of scope rather than economies of scale (Dove, 2001). Where lean operations are usually associated with the efficient use of resources, agile operations effectively respond to a changing environment while being productive at the same time. The idea is to serve ever-smaller niche markets and individual customers without the high cost traditionally associated with customization. Agile organizations are not only capable of successfully implementing change; they are nimble and capable of responding quickly and gracefully to both expected and unexpected events in their environment. The concept of agility arose from flexible and lean manufacturing (Kidd, 1995; Dove, 2001) and was quickly adopted by organizations that produced software in the form of agile systems development (Aoyama, 1998; Cockburn, 2001).

The purpose for reducing IS development or modification lead time is to execute quick responses to the 
incessant changes in the business environment with a view to securing an intercorporate competitive advantage, which is exactly the prime objective of an agile business. In our way of thinking, an agile business cannot be realized unless it has the following three types of quickness: (a) quick recognition of changes in the management environment, (b) quick decision making on countermeasures against these changes, and (c) quick implementation of the countermeasures chosen. In the world of business today, the quickness of (a) depends on information handled by an IS, the quickness of (b) depends on the use of the IS for decision making, and the quickness of (c) depends on the prompt adjustment of the IS itself in line with the chosen countermeasures.

Once realized, these elements of quickness constitute the resources for competitive advantage (Porter, 1980), as does the innovative approach of process re-engineering (Hammer \& Champy, 1993).

When an IS provides an application function $(F)$ that is "utilized effectively" $(U)$, the IS yields the "usefulness" of contributing to the performance of the end-user organization as the resources for competitive advantage. We consider this usefulness as a reward (ISreward) that the end-user organization receives by utilizing its IS appropriately. We then express IS reward as follows:

$$
\text { IS reward }=f(F, U)
$$

This means that $I S$ reward is a mathematical function $(f)$ of the combination of an application function $(F)$ that the IS provides and the organization's ability to utilize the function $(U)$.

\subsubsection{Constraints on Acquiring IS Reward}

Generally, the competitive advantage acquired through ICT may last only for some time before it is imitated. However, other companies face many severe constraints in their imitation efforts. These constraints include not only cost, time, and IS development adaptability (engineers' learning ability of technological and methodological innovation), but also the resistance of the end-user organization concerned and its IS adaptability (end-user's learning ability of IS change).

If these constraints conversely happen to constitute strengths or core competencies (Prahalad\& Hamel, 1990) on the part of a company with competitive advantage, its IS can form a nonporous barrier to entry in intercorporate competition, similar to a barrier to entry from strategic use of ISs (Wiseman, 1985), and will thwart any attempt at imitation by the counterparts of other companies. This barrier can be considered as being represented by the concept of "inimitability," which the resource-based view (Wernerfelt, 1984) pointed out as an element of competitive superiority (Barney, 2002). The cases in which inimitability successfully led to the formation of barriers to entry (e.g., the seat reservation system (SABRE) of American Airlines and the ATM of Citibank) and to their resultant predominance in intercorporate competition, even though for a limited time, were good evidence that the IS of other companies were not flexible enough to follow in the steps of their counterparts in these successful companies. Accordingly, with a view to acquiring competitive advantage, a late starting organization first needs to provide its IS with enough flexibility to overcome these constraints and bring it under control.

\subsection{Strategy for Acquiring IS Value}

\subsubsection{Definition of IS Value}

The aforementioned competitive advantage is called "IS value" in Information Economics (Parker \& Benson, 1988). For the six types of this IS value defined in relation to "business agility," we may provide the following paraphrases.

Value of investment: It is the economic utility that an IS generates for the organization concerned. Quickness of capital recovery (or high rate of turnover) provides the organization with higher business profits.

Value of management information: It represents the utility that an IS generates by providing the critical success factors that affect the success or failure of the business in the form of management information. Quicker acquisition of the information required for decision making when coping with environmental changes enables the organization to take quicker action against these changes.

Value of competition: It means the utility that an IS generates by enabling the organization concerned to catch up with a competitor with a business advantage. Obviously, continuing poor IS efficiency on the part of the organization only aggravates its business disadvantage against the competitor. Here the organization's urgent challenge is to transform its IS into one that is as good as or, preferably, better than that of its competitor.

Value of strategy support: It means the utility from the use of an IS as support for current business strategies. In this context, generally, IS implementation goes hand in hand with changes in standard operating 
procedures(SOPs) and changes in the IS itself. Quick implementation of these changes boosts the efficiency of accomplishing current business strategies.

Value of competitive edge: It means the utility that an IS offers by determining new managerial strategies and new products or methods to outdo its competitor and overcome barriers standing in its way. If competitors are likely to implement equivalent strategies, an organization cannot expect to acquire a competitive edge over them unless it is quicker in taking action.

Value of ITI: It consists of hardware, software, data, and communication networks. ITI thus defined is a prerequisite for the generation of these other values, and its renovation affects the efficiency of an IS in generating them. Because a business today cannot operate without an IS, we assume that a project to change SOPs virtually means a planned change in the IS. Therefore, given a properly renovated ITI, the project would require far lower cost and shorter time than otherwise expected.

Therefore, business agility as an intercorporate competitive advantage cannot be realized unless well-renovated ITI guarantees maximally efficient implementation of IS change at minimal cost and in minimal time. The business value of an IS (hereafter IS value) is generated using a process of an application function working on ITI (Hamilton \&Chervany, 1981). Then, IS value might be represented by the following formula:

$$
\text { IS value }=\frac{f(F, U)}{g(C, T)}=\frac{I S \text { reward }}{g(C, T)}
$$

Where $C, T, F$, and $U$ indicate cost, time, function, and use, respectively. Incidentally, Johanson et al. (1993) defined $I S$ value in terms of quality, service, cost, and cycle time.

The numerator $f(F, U)$ of this formula means IS reward, a function of the combination of an IS function $(F)$ that the organization-wide IS provides and the organization's ability to utilize the IS function $(U)$. The denominator $g(C, T)$ is a function of the cost $(C)$ and time $(T)$ required to develop and maintain the organization's IS. The $I S$ value newly yielded increases accordingly as the value of the numerator $f(F, U)$ increases and/or as the value of the denominator $g(C, T)$ decreases.

The numerator concerns the end-user's IS adaptability. When it is high (low), the numerator is large (small). The denominator concerns IS development adaptability. When it is high (low), the denominator is small (large).

\subsubsection{IS Effectiveness Evaluation}

With respect to the evaluation of IS effectiveness, the methods traditionally utilized were, in the classification of cost/benefit methodology, total quantification with qualitative analysis, information economics, and contribution to corporate performance(Laudon \& Laudon, 2000). However, perception and use of a particular information system can be heavily conditioned by personal and situational variables (Lucas, 1974). This fact makes it difficult to quantitatively evaluate IS effectiveness. However, the following five measures are deemed relatively reliable for this purpose: "high levels of system use"; "user satisfaction with the system"; "favorable attitudes toward the IS function"; "achievement of objectives"; and "financial payoff" (Laudon \& Laudon, 2000). In fact, many IS researchers have shifted their focus to the human and organizational measures of system success, such as information quality, system quality, and the impact of systems on organizational performance (DeLone \& Ephraim, 1992).

These evaluation methods or criteria focus on the numerator of formula (2), which in effect represents the IS use process, i.e., how easily adaptable an IS is for the end-user. Quick use of an adapted IS enables (a) quick recognition of an environment change and (b) quick decision making on countermeasures taken against the change.

However, for all of the research efforts on this adaptability, we know of no established methods that an organization can use to maximize the aforementioned six types of neither "IS value" nor "IS reward".

In contrast, (c) quick implementation of countermeasures chosen to manage environmental changes involves changing an IS itself. Today, ISs are increasingly growing in scale, as are the demands for the modification of existing ISs to manage the incessant changes inside and outside organizations. Unfortunately, however, no systematized methods exist that we can use to minimize the cost and time required to meet change demands, i.e., the denominator of formula (2). Many IS implementations have experienced problems such as failure to deliver by the due date; excess over an estimate; productivity deterioration (increases in backlogs); malfunctioning (activity inability, operational inability, increases in bugs); and system failure (failure of a system to be used as intended) - thus showing that no reliable methods exist to estimate or predict the denominator of formula (2), i.e., the cost and time required for IS implementation and use process. 
Therefore, we refer to the constraints to acquire IS reward as the "penalty of change," which is represented by cost and time as follows:

$$
\text { Penalty Of Change }=g(C, T)
$$

\subsubsection{Definition of IS Flexibility}

Many problems demand detailed analysis concerning both denominator and numerator of formula (2). The basic angles of analysis on each category might be as follows.

The denominator of formula (2) has two interpretations. One interpretation is that quick acquisition of IS value can be achieved by shortening the cycle time (for example, quick decision making, high turnover rate). The other interpretation is that quick acquisition of $I S$ value is achieved through quick change in an application function, i.e., quick change in the IS working on ITI. Fundamentally, we expect these achievements to be accelerated by technological innovation, although they are affected to some extent by the characteristics of the organization concerned.

In contrast, the numerator of formula (2) is interpreted as "the use of the application function." The use process is heavily conditioned by cultural peculiarities, levels of education, and technological proficiency, among others. Therefore, analysis of the effectiveness and efficiency with which the application function is used should focus on human and organizational behavior in relation to the IS.

The denominator of formula (2) is represented by cost and time as the POC to be paid for the change in an IS function. Hereafter, we use the abbreviated notations of "POC" and "IS flexibility" to represent the penalty payable for IS change and the facility of an IS to absorb change demands, respectively.

The alleviation of the problems faced by our IS manager requires reduction in the value of the denominator. As was clearly shown, this requirement can be satisfied by the enhancement of IS flexibility. Then, for our present purpose, leaving out the numerator may enable IS flexibility to be posited as formula (4):

$$
\text { IS flexibility }=\frac{1}{P O C}
$$

The denominator of this formula can be regarded as a penalty that every IS manager needs to pay for changing their organization's IS. Hereafter, we refer to this penalty as "POC" after the fashion of Chryssolouris\& Lee (1992), who used the term in a different context of mechanical engineering. Note that formula (4) represents the relationship between $I S$ flexibility and $P O C$, i.e., the higher the $I S$ flexibility, the smaller the $P O C$, and conversely, the lower the IS flexibility, the larger the POC. Obviously, the larger the reward and the smaller the penalty $(P O C)$, the better it will be. Enhancement of IS flexibility alleviates the POC payable by IS managers such as ours and their other related problems. The formula indicates that $P O C$ is usable as an index of $I S$ flexibility; in other words, IS flexibility, which is the in-built ease required to modify an IS, can be quantitatively evaluated in terms of $P O C$.

\section{IS Flexibility for Future Demands for Change}

As noted in the previous section, to win in intercorporate competition, a user company might pursue an acquisition with the highest IS value. Moreover, the role of its IS division should be to maximize IS flexibility, i.e., minimize future $P O C$.

Here we change our analytic viewpoint to the development and implementation of IS, which play typical roles in an IS division.

\subsection{Outline of Technological Issues Involving IS}

Computer and software vendors have created a succession of booms in systems, methodologies, and services, such as decision support system (DSS), SIS, database management system (DBMS), re-engineering, enterprise resources planning (ERP), and recently, cloud computing. In addition, information technology (IT) innovations such as component-based and service-oriented software architectures (Bieberstein, et al., 2006), Web services (Whiting, 2003), autonomous computing concepts (Horn, 2001), and mobile applications (Siau et al., 2001) promise greater flexibility than the mainframe, client/server, and nonmobile systems they are meant to replace; yet, they require significant upfront investments.

In this process, to stir up an urge in the user companies to use their technologies, the vendors declared, "If you do not jump on the bandwagon, your company will lose an opportunity to be successful".

Have these technologies and methodologies really served, or can they really serve, to remedy problems such as 
those afflicting our IS managers? (See Table 1).

Systems developments have been expanding their targets, all the way from individual business processes within a company and systems integration for an entire company to systems integration beyond corporate boundaries, e.g., from business process reengineering (BPR) to ERP and on to supply chain management (SCM). Moreover, various proposals for innovative technologies and methodologies were made with the intention to boost the productivity of systems development.

However, this new trend has had no decisively favorable effect on the circumstances surrounding the IS manager. One obvious reason is a remarkable surge in labor incurred by the maintenance of renovated systems and a corresponding drain on the reserve of corporate resources needed for further systems renovation (Boehm, 1976). Since the ' $80 \mathrm{~s}$, the need to restore corporate strength has led to a variety of technologies and methodologies intended to enhance the productivity of systems development. These innovative technologies, notably computer-assisted software engineering (CASE), considered not only the development of new systems but also their maintenance. However, it is difficult to state if these efforts could fully satisfy the needs of user companies. If an IS manager's IS division switches to ERP or to a cloud environment, the problems of the IS manager might be alleviated. However, as Table 1 shows, because the IS manager's IS division does not have enough reserve strength to switch to these new technologies, even the manager is criticized by his/her own staff.

Demands for systems development, as we have already noted, have escalated in their scale and complexity, all the way from automation of individual business processes to systems integration for an entire company, and further for an entire industry. Accordingly, this rapid development makes coordination among the people concerned unmanageably complex and leads to negative feedback for the IS manager from within the company. However, despite this circumstance surrounding the IS manager and his/her division, the management simply goads him/her on to unveil long-awaited systems. This situation has generally been the case with IS divisions and their managers since the ' $80 \mathrm{~s}$. The IS manager's problems involve not only development of new systems but also maintenance of the existing IS. The manager's mission, of which he/she is well aware, is to keep his/her organization-wide IS well organized and to develop it further. However, the issue is that the IS manager faces many problems and is at his/her wit's end in developing any workable solution for these problems.

\subsection{IS Success and Failure}

Organizational innovation is difficult and complex to achieve. It involves more than simply purchasing technology. To reap the benefits of technology, innovations must be utilized and managed properly, which in turn, requires changes in the values, norms, and interest-group alignments of the organization (Laudon \& Laudon, 2000).

The Lewin and Schein model (Keen, 1981) explains the need to unfreeze organizations (i.e., create a climate of change) before introducing an innovation (i.e., problem analysis and solution design), quickly implementing it, and refreezing or institutionalizing the change (i.e., solution).

Figure 1 illustrates the strategy for achieving information system success in a process to implement innovative changes in an organization. To achieve "IS success" in this figure, an adaptive IS function has to be designed to acquire "IS reward" from "Unfreezing" to "Change," and then has to be introduced and implemented in the organization during "Refreezing" for its proper use process.

In the process illustrated in formula (2), IS value increases, meaning that $P O C$ is smaller, and thus, IS reward is larger. When "IS flexibility" was at a maximum, the result of this process (i.e., success or failure) depended purely and simply on the factors of organizational science. That is, without the constraints of $P O C$, repeating trial and error until a new BP is successfully implemented in an organization is possible.

Needless to say, quick acquisition of "IS reward," as well as quick IS modification, is better. However, in some organizations, drastic change may lead to quick success, whereas in others, gradual change may yield a larger "mid-term IS reward."

\subsection{Flexibility of Organization-Wide IS}

\subsubsection{Mechanism to Yield Mid-Term IS Reward}

Figure 2 illustrates formula (1) as representing IS reward and explains the mechanism to yield mid-term IS reward using the following three steps of "IS and Organizations," shown in the dotted-line boxes; "Environment Change," shown in the single-line boxes; and "Flexibility," shown in the double-line box to emphasize that it is a crucial property. And we assume that the "Adaptabilities" in this figure are the critical constraints for upgrading the IT business aliment maturity level of companies. 


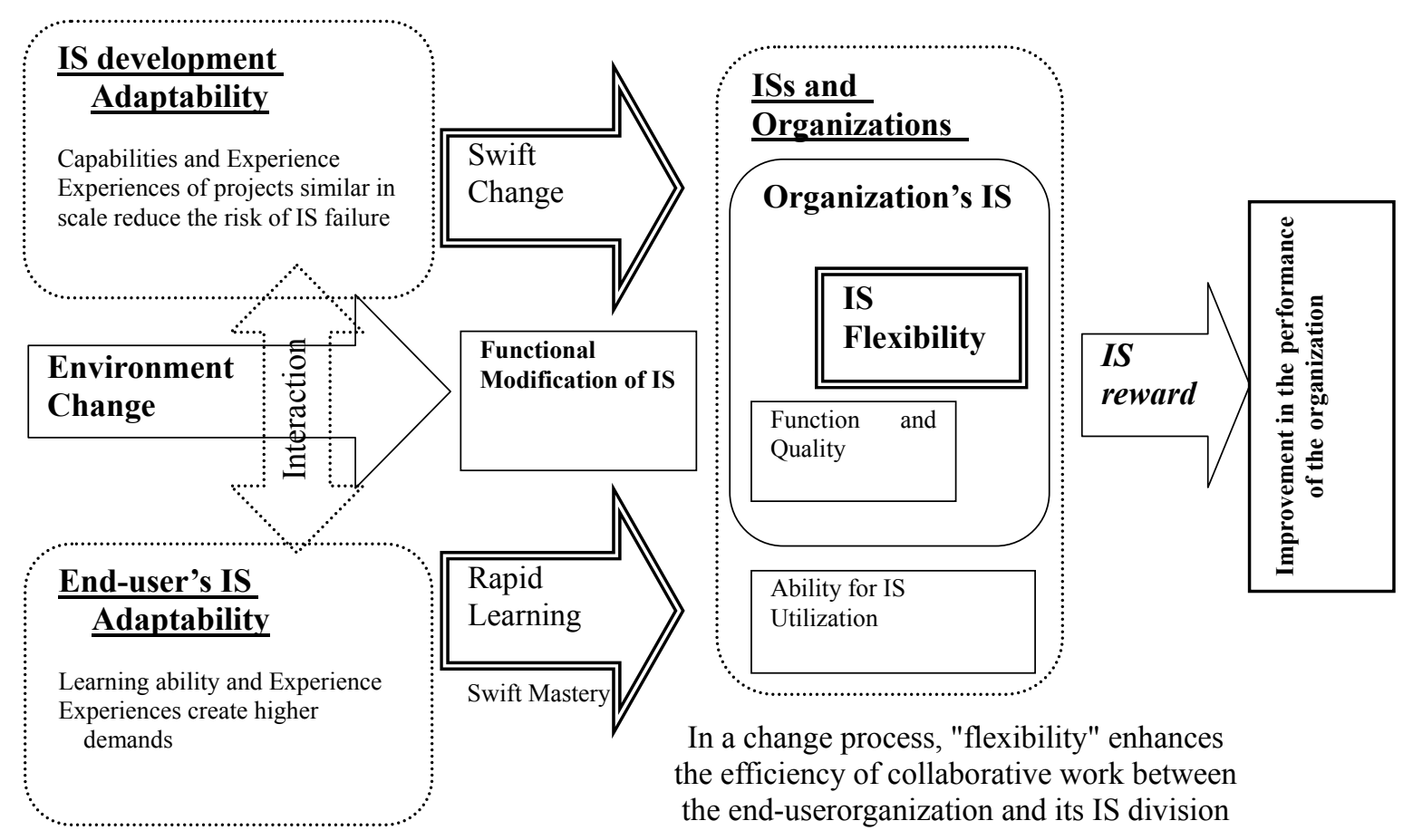

Figure 2. Mechanism to yield mid-term IS reward

Note: Arranged to illustrate organizational resistance and change in BPR based on the Lewin and Schein model. Source: Keen (1981)).

IS and Organizations: Simply put, "IS development adaptability" and "End-user IS adaptability" shown in the dotted-line box mean the following: IS and organizations have a mutual influence on each other. On the other hand, IS must be aligned with the organization to provide the information needed by the important groups in the organization. At the same time, the organization must be aware of and must open itself to the influence of IS to benefit from new technologies. IS affects organizations, and organizations necessarily affect the design of systems. However, in actuality, a large number of mediating factors that influence the interaction between IS and organizations exist. These factors include the organization's structure, SOPs, politics, culture, surrounding environment, and management decisions. After all, managers decide on the systems to be built, their functionality, their implementation, and so forth. Largely, managers and organizations choose the "computer impact" as the IS reward that they want (or at least receive the impact they deserve). Sometimes, however, the outcomes are the result of pure chance and of both good and bad luck (Laudon \& Laudon, 2000).

To acquire "IS reward," "IS Function and Quality" have to be adaptive to the organization, and the organization has to be able to utilize them properly (i.e., "IS reward" is the result of the combination of "IS Function and Quality" and "Ability for IS Utilization," shown in the right-hand dotted-line box).

Environment change: An incessantly changing business environment urges organizations to modify their IS functions ("Functional Modification of IS," shown in the central rectangular box). Then, organizations might fortunately acquire $I S$ reward if they can successfully accomplish the process in Figure 1. However, this type of project risks failure.

The success or failure of IS implementation in a business organization depends on the interaction between the adaptability of its IS development and the adaptability of its end-user. This interaction involves actual experience with IS development and use.

Previous studies on the relationship between technology and the end-user organization revealed that previous experience with projects implemented on similar scales reduced the risk of failure (Cronan, 1990). This result suggests that hands-on experience fosters the IS development adaptability of an organization. As for the interaction in question, a newly renovated IS induces the end-user organization to manage to use it in one way or another, and this effort serves to upgrade both adaptability of its IS and demands for changes in the IS. In turn, the end-user's upgraded demands for IS renovation stimulate more advanced technological innovation within the IS division. 
This process enables the interaction of an organization's technology and its end-user to elevate both IS adaptability of the latter and capabilities of the former through a reciprocal upgrade of each other's experience. This process also shows how cumulative actual IS development and use experience contribute to enhancing the performance of the business organization concerned, as suggested by the hypothesis of the "experience curve effect."

Flexibility as an attribute of IS: We assume that a change in the business environment has given rise to the need for adjustments to an organization's IS. In such a situation, if the IS is "flexible" enough to modify its function to match the end-user's IS adaptability, this organization can expect to accomplish a quicker response to the demand for environmental change and gain a larger reward (IS reward) than its less well-equipped competitors faced with the same need for a system adjustment. In Figure 2, which illustrates an organization-wide IS, the concept of "IS flexibility" is shown in the double-line box to emphasize that it is a crucial property that an organization's IS should possess and that enables it to quickly respond to environmental changes. Simply put, this concept denotes the property of changeability (easiness of change) built into the architecture of an IS that allows prompt modification of its functions in response to actual change demands.

\subsubsection{Required Property of IS Flexibility}

To clarify what we mean by the property of flexibility that we believe an organization-wide IS should possess, we hypothesize on possible responses to an environmental change by the following four types of organizations with different combinations of IS development adaptability and end-users' IS adaptability.

\section{Both IS development adaptability and end-user IS adaptability are high.}

Obviously, this organization's IS can efficiently use its flexibility to modify its functions as required. Given the high IS adaptability, the end-user is able to promptly acquire proficiency in using the modified function in its successful attempt to respond to environmental changes.

\section{IS development adaptability is high and end-user IS adaptability is low.}

The organization's IS can quickly modify its function that might ideally be able to quickly accommodate environmental changes. However, because of low end-user IS adaptability, the organization needs a long time to master the use of the modified function, for which purpose it must gradually accumulate its use experience. Inevitably, this mismatch will result in a delay in the organization's response to environmental changes.

However, if the IS has sufficient "flexibility" built into it, that is, if the IS is redesigned to permit ad hoc iterative/incremental modifications, it could provide functional modification in phases and the end-user could make progress in learning its use. Despite inevitable trial and error, this process saves the end-user unreasonable time and effort when attempting to master the use of the IS.

Built-in flexibility of an IS is a prerequisite for the end-user's "swift mastery" of its use, as shown in Figure 2.

III. IS development adaptability is low and end-user IS adaptability is high.

Obviously, the functional modification of this organization's IS will experience a delay, consequently resulting in a delay in the response to environmental changes. The problem is that IS modification will require a long time given the low level of technological capabilities (i.e., lack of experience).

However, if the IS is restructured to be highly changeable to such a degree that even new recruits are able to modify it as easily and as quickly as skilled engineers, they would quickly mature into assets of the organization. Therefore, for an organization of this type, low IS development adaptability does not necessarily constitute a serious impediment to system change. Thus, the built-in changeability of an IS could be expected to alleviate the problem of a delayed response, which would otherwise occur, to an environmental change and provide the key to swift IS change, as shown in Figure 2.

\section{Both IS development adaptability and end-user IS adaptability are low.}

This double weakness makes it difficult for the organization to take swift action regarding environmental change.

The only possible way to overcome these impediments to a prompt response is to restructure the IS itself in the same way as above and to accumulate practical experience in its renovation and use.

The previous analysis might allow us to tentatively define IS flexibility by providing the following two characterizations.

An organization's IS should have sufficient built-in changeability to allow phasing of its functional modifications in keeping with the progress that the end-user can make in learning its use. This process will 
ensure a smooth trial-and-error-prone learning process for the end-user.

An IS should have sufficient built-in changeability to allow even new recruits to make a functional modification as easily as skilled engineers. IS flexibility may well prevent low adaptability to IS development from being a serious impediment to modification of a current system.

In a highly computerized modern society, satisfying these requirements constitutes a critical success factor that may determine whether or not an organization can quickly respond to environmental changes by utilizing its IS.

\subsubsection{How IS Flexibility Can Alleviate the IS Manager's Problems}

To examine whether or how enhancement of "IS flexibility," as defined above, might contribute to the alleviation of our IS manager's problems (as shown in Table 1), we consider the following two aspects of IS management.

\section{1) IS adaptability}

Function and quality: Low opinions such as "This system does not meet our needs," and "Why can't we do it ourselves when our competitor is already doing it?" are probably attributable to the failure of the system to meet technical requirements (e.g., requirement definition, functional design, development speed) and to meet the level of the end-user's IS adaptability. Enhancement of IS flexibility makes it easier to provide (build in or modify) functions and quality that the end-user demands and to incrementally add on IS changes (e.g., adding a new function, modifying a current function) until the end-user's ultimate satisfaction is obtained.

\section{2) IS development adaptability}

Customer service: The low opinion that the IS takes intolerably long to meet their need for a functional modification is attributable to the inadequacy of the organization's IS development adaptability. Built-in flexibility of the IS, if realized, could reduce the lead time on its modification and provide customer service on time and at low cost.

Development capability: "It takes us at least one year to train a new recruit to be a full-fledged worker." As this complaint from an IS staff member suggests, educating new recruits takes extra time from senior engineers and reduces the productivity of their primary business operations. In fact, this underproductivity creates a vicious circle of chronic work overload that burdens our IS division. However, important as it is to educate recruits with the aim of equipping them with high IS development adaptability, higher priority should instead be given to the construction of an IS with built-in flexibility. Modification of such a flexible IS would not necessarily require high IS development adaptability and could even be handled by new recruits. Therefore, adequate IS flexibility in this sense obviates the problem of an engineer's insufficient experience, and absorbs skilled workers' high cost and low-skilled workers' underproductivity, which results from trial and error. Therefore, because the organization's IS could be modified at low cost and in a short period, our IS division could expect to free itself from the chronic work overload about which its staff complains.

The aforementioned analysis might allow us to characterize IS flexibility as follows.

Suppose an organization's IS already has adequate flexibility built into its architecture when a demand for its adjustment occurs.

The IS division can make the modified IS service available to the end-user with little lead time and at low cost (i.e., disposal of the change demand does not require high IS development adaptability and can even be handled by a new recruit).

\subsubsection{What Our Manager Has to Do}

Irrespective of their size, most organizations today utilize their own IS for business management. Stating that without the aid of an IS, no organization can hope for efficient and effective business management, is no exaggeration. Therefore, an organization's performance can even be defined as a product of the interaction of the business accomplished attributable largely to the utilization of the function of and the quality provided by its IS, as well as the $P O C$ needed to accomplish it.

The alleviation of the problems faced by our IS manager requires the reduction of $P O C$. We have clearly shown that this requirement can be satisfied by the enhancement of IS flexibility.

Incidentally, each IS change demand $X_{i}(1 \leq i \leq n)$ requires $P O C$. From the viewpoint of IS engineers, each change demand may seem to occur suddenly. Therefore, we describe the sum of $P O C$ for possible future change demands probabilistically as follows: 


$$
P O C=\sum_{i=1}^{n} P O C\left(X_{i}\right) \operatorname{Pr}\left(X_{i}\right)
$$

Here $\operatorname{Pr}\left(X_{i}\right)$ is the probability that the change demand $X_{i}$ will occur in the future. However, this probability is derived from the business plan of the organization to which the IS division belongs. Moreover, it is a subjective probability that the IS division can consider in its decision making. Therefore, we translate formula (5) into the next question.

"How flexible should we make the existing IS of our organization in order to absorb possible future change demands?"

Our IS manager's worry is that the solution to accomplish the role of his/her division cannot be found. Alleviating our manager's problems requires that the IS division participate in the development of its organization's midterm business plan, on which the policy for the necessary and sufficient IS flexibility must be built. Therefore, our IS manager must, consequently, be able to explain to his/her executives why information systems need to be flexible.

In this connection, a caveat is in order. The literature contains an observation to the effect that, "Data collected from 293 IT managers showed that the range of managerial ITI capabilities, which were positively affected by all areas of IT personnel knowledge and skills, were responsible for the competitive impacts of the ITI-enabled flexibility. Multi-group analyses showed that large organizational size or reporting to the CEO reduced the positive effects of the range of managerial ITI capabilities on competitive impacts" (Fink \& Neumann, 2009). This observation suggests that when attempting to explain the necessity of IS flexibility to a CEO, the IS manager must be careful with not only the CEO's tendency for management decisions, but also the organization's structure, SOPs, politics, culture, and surrounding environment to which he/she belongs.

$\mathrm{He} / \mathrm{she}$ has to know the answer to the next question of how to make information systems flexible.

\section{Conclusion}

This study analyzed the problems faced by a typical IS manager. The manager's problems were found to have arisen from the failure of his IS division to fully meet the needs of his corporate end-users. The end-users strive to realize a competitive advantage through sustained business agility and adaptability to dizzying changes in the business environment. However, the IS division is not technologically capable enough to promptly deliver IS modifications that meet end-users' ever-changing needs, and the end-users themselves are not technologically literate enough to quickly acquire proficiency in using the modified service.

A review of the evolution of information technology that we have undertaken with a view to determining a remedy for this state of affairs revealed that increased coverage of IS led to coordination difficulties among the people concerned. This increased coverage also led to an excessive workload that burdens an IS division with respect to modification and maintenance of its current system.

On the basis of this finding, we attempted a detailed analysis of the pressing need for IS architectural renovation and the need to structure the IS architecture into one with greater built-in flexibility to facilitate IS engineers to make prompt functional modifications and end-users to easily acquire proficiency in using the modified functions.

In the final part of our paper, as a prelude to Part 2, we introduced the concept of $P O C$ to define the relationship between the flexibility and utility of IS modifications. In Part 2, we address our second question of how, in practical terms, information systems can be made flexible.

\section{References}

Allen, B. R., \& Boynton, A. C. (1991). Information Architecture: In Search of Efficient Flexibility. MIS Quarterly, 15(4), 435-445. http://dx.doi.org/10.2307/249447

Anderson, D. J. (2004). The Four Roles of Agile Management. Cutter It Journal, 17(7), 11-17.

Aoyama, M. (1998). Web-based Agile Software Development. IEEE Software, 15(6), 55-65. http://dx.doi.org/10.1109/52.730844

Barney, J. B. (2002). Gaining and Sustaining Competitive Advantage (2nd ed.). Upper Saddle River, New Jersey: Prentice Hall.

Bieberstein, N., Bose, S., Fiammante, M., Jones, K., \& Shah, R. (2006). Service-Oriented Architecture Compass. Upper Saddle River, New Jersey: Pearson. 
Boehm, B. W. (1976). Software Engineering. IEEE Transactions on Computers, 25(12), 1226-1241. http://dx.doi.org/10.1109/TC.1976.1674590

Byrd, T. A., \& Turner, D. E. (2000). Measuring the Flexibility of Information Technology Infrastructure: Exploratory Analysis of a Construct. Journal of Management Information Systems, 17(1), 167-208.

Chryssolouris, G., \& Lee, M. (1992). An Assessment of Flexibility in Manufacturing Systems. Manufacturing Review, 5(2), 105-116.

Cockburn, A. (2001). Agile Software Development. Reading, UK: Addison-Wesley.

Conboy, K. (2009). Agility from First Principles: Reconstructing the Concept of Agility in Information Systems Development. Information System Research, 20(3), 329-354. http://dx.doi.org/10.1287/isre.1090.0236

Cronan, T. P., \& Douglas, D. E. (1990). End-user Training and Computing Effectiveness in Public Agencies: An Empirical Study. Journal of Management Information Systems, 6(4), 21-40.

DeLone, W. H., \& McLean, E. R. (1992). Information System Success: The Quest for the Dependent Variable. Information Systems Research, 3(1), 60-95. http://dx.doi.org/10.1287/isre.3.1.60

Dove, R. (2001). Response Ability-The Language, Structure, and Culture of the Agile Enterprise. New York: Wiley.

Duncan, N. B. (1995). Capturing Flexibility of Information Technology Infrastructure: A Study of Resource Characteristics and Their Measure. Journal of Management Information Systems, 12(2), 37-57.

Economist. (2004, October 30). Make It Simple: A Survey of Information Technology.

Fink, L., \& Neumann, S. (2009). Exploring the Perceived Business Value of the Flexibility Enabled by Information Technology Infrastructure. Information and Management, 46(2), 90-99. http://dx.doi.org/10.1016/j.im.2008.11.007

Furukawa, M. (1989). Strategy of IS Manager in a Factory: the Mission of IS Division. Computer Report, 29(10), 39-43.

Furukawa, M. (2000). Evaluating IS Effectiveness by Means of the Measure of Flexibility. The proceedings of the Fourth Pacific Asia Conference on Information Systems (pp. 333-347). Hong Kong.

Furukawa, M., \& Minami, A. (2012). Management Agility Depends on Well-Renovated IT Infrastructure. Computer Technology and Application, 3(8).

Gebauer, J., \& Schober, F. (2006). Information System Flexibility and the Cost Efficiency of Business Processes. Journal of the Association for Information Systems, 7(3), 122-147.

Goldratt, E. M. (1997). Critical Chain. Great Barrington, MA: North River Press.

Haeckel, S. H. (1999). Adaptive Enterprise: Creating and Leading Sense-and-Respond Organizations. Boston: Harvard Business School Press.

Hamilton, S., \& Chervany, N. C. (1981). Evaluating Information System Effectiveness-Part 1: Comparing Evaluation Approaches. MIS Quarterly, 5(3), 55-69. http://dx.doi.org/10.2307/249291

Hammer, M., \& Champy, J. (1993). Reengineering the Corporation: A Manifesto for Business Revolution. New York: Harper Collins.

Horn, P. (2001). Autonomic Computing: IBM's Perspective on the State of Information Technology. White Paper, IBM T. J. Watson Research Center, Yorktown Heights, NY.

Hulet, L. (2004). Agile Development: Lessons Learned from the First Scrum. Development, 5, 1-4.

Johanson, H. J., McHugh, P., Pendlebury, A. J., \& Wheeler, W. A. (1993). Business Process reengineering: break point strategies for market dominance (pp. 4). New York: Wiley.

Keen, P. G. W. (1981). Information Systems and Organizational Change. Communication of the ACM, 24(1) 24-33. http://dx.doi.org/10.1145/358527.358543

Kidd, P. T. (1995). Agile Manufacturing: Forging New Frontiers. London: Addison-Wesley.

Laudon, K. C., \& Laudon, J. P. (2000). Management Information Systems: Organization and Technology in the Networked Enterprise (6th ed.). Upper Saddle River, New Jersey: Prentice Hall.

Lucas, H. C. Jr. (1974). Toward Creative Systems Design. Columbia University Press.

Mathiassen, L., \& Pries-Heje, J. (2006). Business Agility and Diffusion of Information Technology. European 
Journal of Information Systems, 15, 116-119. http://dx.doi.org/10.1057/palgrave.ejis.3000610

Palanisamy, R., \& Sushil. (2003). Achieving Organizational Flexibility and Competitive Advantage through Information Systems. Journal of Information and Knowledge Management, 2(3), 261-277. http://dx.doi.org/10.1142/S0219649203000358

Parker, M. M., \& Benson, R. J. (1988). Information Economics: Linking Business Performance to Information Technology. New Jersey: Prentice Hall.

Porter, M. E. (1980). Competitive Strategy: Techniques for Analyzing Industries and Competitors. New York: Free Press.

Prahalad, C. K., \& Hamel, G. (1990). The Core Competence of the Corporation. Harvard Business Review.

Robey, D., \& Boudreau, M. C. (1999). Accounting for the Contradictory Organizational Consequences of Information Technology: Theoretical Directions and Methodological Implications. Information Systems Research, 10(2), 167-185. http://dx.doi.org/10.1287/isre.10.2.167

Robinson, W. N., \& Pawlowski, S. D. (1999). Managing Requirements Inconsistency with Development Goal Monitors. IEEE Transactions on Software Engineering, 25(6), 816-835. http://dx.doi.org/10.1109/32.824411

Rumbaugh, J., Blaha, M., Premerlani, W., Eddi, F., \& Lorensen, W. (1991). Object-Oriented Modeling and Design. Englewood Cliffs, New Jersey: Prentice-Hall.

Sharifi, H., \& Zhang Z. (2001). Agile manufacturing in practice: Application of a methodology. International Journal of Operations \& Production Management, 21(5/6), 772-794. http://dx.doi.org/10.1108/01443570110390462

Siau, K., Lim, E., \& Shen, Z. (2001). Mobile Commerce: Promises, Challenges, and Research Agenda. Journal of Database Management, 12(3), 4-14. http://dx.doi.org/10.1108/01443570110390462

Silver, M. S. (1991). Systems that Support Decision Makers: Description and Analysis. Chichester, United Kingdom: Wiley.

Soh, C., Sia, S. K., Boh, W. F., \& Tang, M. (2003). Misalignments in ERP Implementation: A Dialectic Perspective. International Journal of Human-Computer Interaction, 16(1), 81-100. http://dx.doi.org/10.1207/S15327590IJHC1601_6

Takeuchi, H., \& Nonaka, I. (1986). The New New Product Development Game.Harvard Business Review, 64(1), 137-146.

Wernerfelt, B. A. (1984). Resource-based View of the Firm. Strategic Management Journal, 5, 171-180. http://dx.doi.org/10.1002/smj.4250050207

Whiting, R. (2003). Money Machines. Information Week, 34-44.

Wiseman, C. M. (1985). Strategy and Computers: Information Systems as Competitive Weapons. Homewood, Illinois: Irwin Professional Pub.

\section{Copyrights}

Copyright for this article is retained by the author(s), with first publication rights granted to the journal.

This is an open-access article distributed under the terms and conditions of the Creative Commons Attribution license (http://creativecommons.org/licenses/by/3.0/). 